\title{
Study of the Comparison of Epidural Ropivacaine and Bupivacaine for Epidural Analgesia after Total Knee Arthroplasty: A Prospective, Randomized, Single Blind Controlled Study
}

\author{
Dr B.Girish $^{1}$, Dr P. Krishna Prasad ${ }^{2}$ \\ ${ }^{1}$ Post graduate in MD Anaesthesiology, Rangaraya Medical College, Kakinada, India \\ ${ }^{2}$ Associate professor, Department of Anaesthesiology, Rangaraya Medical College, Kakinada (Corresponding author)
}

\begin{abstract}
Aim: To compare the efficacy of Bupivacaine 0.125\% (Group B) versus $0.2 \%$ Ropivacaine (Group R), in terms of pain scores, requitement of rescue analgesia, related adverse effects, and duration of postoperative hospital stay. Methods: 100 patients were randomly allocated into two groups of 50 each. Group $B$ received $0.125 \%$ bupivacaine epidurally. Group $R$ received $0.2 \%$ ropivacaine epidurally for postoperative pain relief. All patients were monitored for postoperative pain by the visual analog scale (VAS), requirement of rescue analgesia, hemodynamic parameters and adverse effects. Results: VAS pain scores were comparable in Group B, and Group R.requirement of rescue analgesia werecomparable in Group $R$ and Group B. Adverse effects such as hypotension and delayed motor block was higher in Group B when compared to group $R$. Conclusion: Ropivacaine $0.2 \%$ and bupivacaine $0.125 \%$ were equally efficient in terms of VAS pain scores, rescue analgesic requirement, and duration of postoperative hospital stay, but ropivacaine had a better safety profile in terms of less hypotension and lesser motor block.
\end{abstract}

Keywords: Bupivacaine, Epidural, Ropivacaine, Total knee arthroplasty

\section{Introduction}

Pain is by far one of the most common and distressing symptoms of disease. Effective pain management is a critical component of postoperative care and contributes to fewer postoperative complications. The current trend in postoperative pain is multimodal analgesia. Epidural opioids have been used, but the associated major side effects, such as sedation, itching, urinary retention, nausea, vomiting, and respiratory depression have limited its widespread use. Epidural analgesia has become a standard of care for total knee replacement surgeries and is utilized by multiple modes of delivery including bolus injection, continuous injection, or patient-controlled infusion. [1, 5$]$ Bupivacaine has been used successfully for many years for this purpose, in concentrations ranging from $0.0625 \%$ to $0.25 \%$.[4] Cardiac system and central nervous system (CNS) adverse effects related to bupivacaine have led to development of relatively safer drugs such as ropivacaine and levobupivacaine.[4]Ropivacaine is a newer long-acting amide linked local anaesthetic agent. It is a pure $S$ enantiomer of propivacaine with greater differentiation between sensory and motor blocks and with a better margin of safety due to reduced toxic potential. This study is aimed at comparing the efficacy of these two local anaesthetics at equipotent doses for epidural analgesia after TKA.

\section{Materials and Methods}

After obtaining hospital ethics committee approval and written informed consent, patients were randomly allocated to two groups of 50 each. Group B received $0.125 \%$ bupivacaine epidurally for postoperative pain relief. Group $\mathrm{R}$ received $0.2 \%$ ropivacaine with epidurally for postoperative pain relief.

Inclusion Criteria: Patients of ASA grades I to II of both sexes undergoing elective TKA and giving written consent were included in the study.

Exclusion Criteria: Patients having severe cardiorespiratory illness, coagulation disorders, history of spine surgery, vertebral deformities, infection at the local site, and with allergies, to amide, local anaesthetics were excluded from the study.

Preoperative Assessment: All patients were preoperatively assessed for routine laboratory blood investigations, chest Xray, 12 lead electrocardiogram (ECG),Patients were kept fasting for 8 hours for solids and 4 hours for clear liquids prior to the surgery.

Monitoring: All patients were continuously monitored for Heart rate (HR), Respiratory rate (RR), and oxygen saturation, Noninvasive blood pressure and ECG.

\subsection{Methods}

On the day of surgery, IV access was secured preoperatively with 20 G IV cannula, Patients were preloaded with $500 \mathrm{~mL}$ of Ringer's lactate prior to spinal anaesthesia.

All patients received combined spinal-epidural anaesthesia in sitting position, under all aseptic precautions, in L3 4 
intervertebral space. An epidural catheter (16 G) was inserted and kept 3 to $5 \mathrm{~cm}$ into the epidural space after confirming with the loss-of-resistance technique to air.

After the completion of surgery, the epidural infusion was started when the sensory block regressed to T12-L1. Continuous epidural infusion was started using a syringe infusion pump with either $5 \mathrm{~mL} /$ hour of $0.125 \%$ bupivacaine or $8 \mathrm{~mL} /$ hour of $0.2 \%$ ropivacaine. The dose of the epidural infusion was titrated as per the patients' pain scoring. IV tramadol $50 \mathrm{mg}+\mathrm{IM}$ diclofenac given for rescue analgesia.

The following were observed and noted:

1) Visual analog scale (VAS) pain scores were assessed and recorded every 4 hourly.

2) Other related adverse effects such as hypotension and delayed motor recovery were also recorded. Hypotension was managed by fluid bolus and injection mephentermine $3 \mathrm{mg}$ boluses if required.

3) Requirement of rescue analgesia (IV tramadol 50mg+IM diclofenac).

\subsection{Statistical Analysis}

The Following statistical tests of significance are used.

- Unpaired t-test for comparison between two groups (for comparison of means between two groups, numerical data which are normally distributed).

- Mann-Whitney U-test for comparison between two groups (for comparison of means between two groups, numerical data which are not normally distributed).

- Chi-square test (for comparison of proportions between two groups, categorical data).

\section{Results}

The mean age and sex distribution were comparable in two groups

\subsection{Demographic data}

\begin{tabular}{|c|c|c|c|}
\hline parameters & $\begin{array}{c}\text { Bupivacaine } \\
0.125 \%\end{array}$ & $\begin{array}{c}\text { Ropivacaine } \\
0.2 \%\end{array}$ & $\begin{array}{c}\mathrm{P} \\
\text { value }\end{array}$ \\
\hline Mean age (years) \pm SD & $62.24 \pm 8.28$ & $62.12 \pm 8.34$ & 0.94 \\
\hline Sex & & & \\
Male & $15(70 \%)$ & $14(69 \%)$ & 0.895 \\
female & $35(30 \%)$ & $36(31 \%)$ & \\
\hline
\end{tabular}

\section{Visual Analog Scale pain scores}

Group R and B had comparable average VAS scores ( $\mathrm{P}=$ 0.114 )

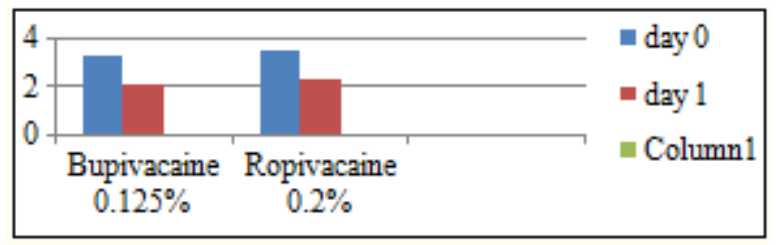

Figure 1: Daily average visual analog scale mean pain scores

\begin{tabular}{|c|c|c|c|}
\hline & Bupivacaine $0.125 \%$ & Ropivacaine $0.2 \%$ & $\mathrm{P}$ value \\
\hline Day 0 & 3.33 & 3.6 & 0.114 \\
\hline Day 1 & 2.11 & 2.32 & 0.075 \\
\hline
\end{tabular}

\section{Requirement of rescue analgesia:}

Groups R and B were comparable in terms of requirement of rescue analgesia (i.v. tramadol $50 \mathrm{mg}, \mathrm{i} . \mathrm{m}$. diclofenac) $\mathrm{p}$ value $=0.22$

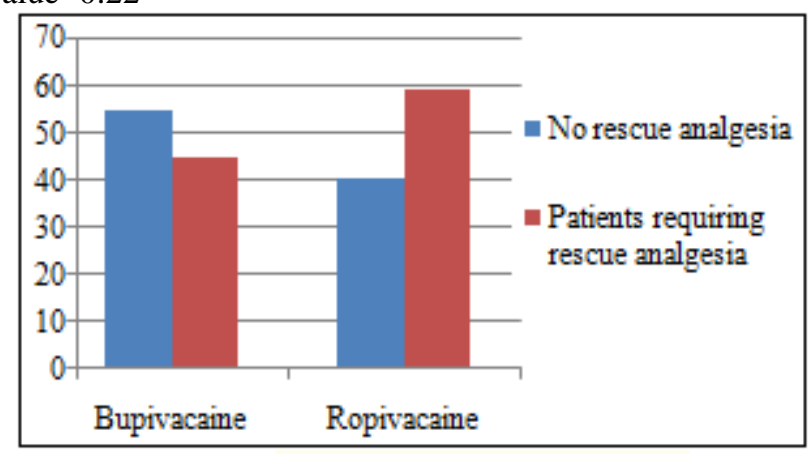

Figure 2: Rescue analgesia requirement

\begin{tabular}{|c|c|c|}
\hline & Bupivacaine $0.125 \%$ & Ropivacaine $0.2 \%$ \\
\hline $\begin{array}{c}\text { Patients not requiring } \\
\text { rescue analgesia }\end{array}$ & $55.1 \%$ & $40.5 \%$ \\
\hline $\begin{array}{c}\text { Patients requiring } \\
\text { rescue analgesia }\end{array}$ & $44.9 \%$ & $59.5 \%$ \\
\hline
\end{tabular}

$\mathrm{p}$ value 0.22

\section{Postoperative hospital stay}

Groups R and B had comparable days of postoperative hospital stay $(\mathrm{p}$ value $=0.13$ )

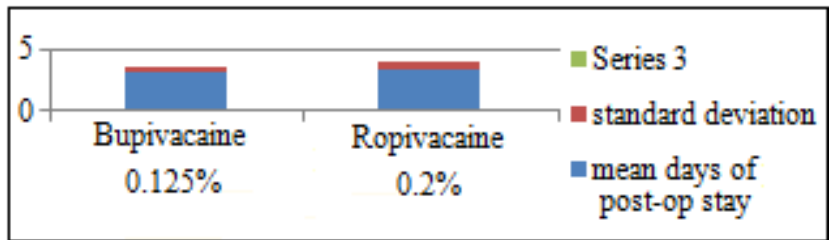

Figure 3: Number of days of postoperative hospital stay

\begin{tabular}{|c|c|c|}
\hline & $\begin{array}{c}\text { Bupivacaine } \\
0.125 \%\end{array}$ & $\begin{array}{c}\text { Ropivacaine } \\
0.2 \%\end{array}$ \\
\hline Mean days of post-op stay & 3.29 & 3.5 \\
\hline Standard deviation & 0.442 & 0.523 \\
\hline
\end{tabular}

p value: 0.13

\section{Adverse effects}

Incidence of hypotension was significantly higher in Group B compared to Group R ( $\mathrm{p}$ value 0.025). Delayed motor block was observed in $7.3 \%$ patients in Group B compared to $2.3 \%$ in Group $\mathrm{R}(\mathrm{P}=0.076)$.

\begin{tabular}{|c|c|c|c|}
\hline Adverse effect & Bupivacaine 0.125\% & Ropivacaine 0.2\% & P value \\
\hline hypotension & $5(9.8 \%)$ & $1(2.3 \%)$ & 0.025 \\
\hline $\begin{array}{c}\text { Delayed motor } \\
\text { block }\end{array}$ & $4(7.3 \%)$ & $1(2.3 \%)$ & 0.046 \\
\hline
\end{tabular}

\section{Discussion}

Epidural analgesia is more efficacious than systemic analgesia for post-operative pain relief in the lower limb orthopedic surgeries.[1] Choi et al. in their systemic review reported that patients receiving epidural analgesia in elective knee and hip surgeries had less pain at rest, especially in the 
first 4-6 h post-operatively.[1]A continuous epidural infusion of LA with rescue doses is the most common mode of delivery although patient-controlled epidural analgesia appears to be the most cost-effective in this regard.[5]

Bupivacaine has been a standard LA drug used for providing epidural analgesia and anesthesia in numerous scenarios including abdominal surgeries, lower limb surgeries.

Ropivacaine is an amide group LA and is a pure left isomer. It is less lipophilic compared to bupivacaine. This accounts for its reduced propensity to block larger myelinated motor nerve fibers and thus theoretically has better motor sensory differentiation and minimal potential to cause CNS and cardiac toxicity.[4]

In our study Groups R and B had similar VAS scores. Bertini et al. in their study comparing $0.2 \%$ ropivacaine and $0.2 \%$ bupivacaine in hip replacement surgeries had similar findings, in terms of equal analgesic effect.[6] Kanai et al. also reported significantly less maximal VAS scores in $0.2 \%$ ropivacaine with fentanyl, compared with $0.125 \%$ bupivacaine [7]

In the present study, requirement of rescue analgesia Requirements in Groups $\mathrm{R}$ and $\mathrm{B}$ were lower but comparable. Sawhney et al. brought out that $0.2 \%$ ropivacaine had the least rescue analgesia requirement compared to other groups[8].

Number of days of post-operative stay were comparable in both the groups. not much literature regarding analysis of number of days of post-operative stay, but general consensus is that use of ropivacaine leads to faster recovery and shorter post-operative stay.[9]

Incidence of adverse effects such as delayed or prolonged motor block (which might delay ambulation) with bupivacaine as compared to ropivacaine[3,10].In the present study, delayed/prolonged motor block and hypotension were both observed to significantly higher in Group B compared to Group R.

\section{Conclusion}

Ropivacaine $0.2 \%$ and bupivacaine $0.125 \%$ were equally efficacious in terms of VAS pain scores, rescue analgesic requirement, and duration of postoperative hospital stay, but ropivacaine had a better safety profile in terms of less hypotension and lesser motor block. Hence, it is recommended as the currentbest possible choice for use in epidural analgesia in lower limb surgeries such as total knee replacement surgeries.

\section{References}

[1] Choi PT, Bhandari M, Scott J, Douketis J. Epidural analgesia for pain relief following hip or knee replacement. Cochrane Database Syst Rev 2003;3:CD003071.

[2] Korean Knee Society. Guidelines for the management of postoperative pain after total knee arthroplasty. Knee SurgRelat Res 2012;24:201-7.
[3] Bertini L, Mancini S, Di Benedetto P, Ciaschi A, Martini O, Nava S, et al. Postoperative analgesia by combined continuous infusion and patient-controlled epidural analgesia (PCEA) following hip replacement: Ropivacaine versus bupivacaine. Acta AnaesthesiolScand2001;45:782-5.

[4] Casati A, Putzu M. Bupivacaine, levobupivacaine and ropivacaine: Are they clinically different? Best Pract Res Clin Anaesthesiol. 2005;19:247-68.

[5] Mulroy MF. Epidural opioid delivery methods: Bolus, continuous infusion, and patient-controlled epidural analgesia. Reg Anesth. 1996;21(6 Suppl):100-4.

[6] Bertini L, Mancini S, Di Benedetto P, Ciaschi A, Martini O, Nava S, et al. Postoperative analgesia by combined continuous infusion and patient-controlled epidural analgesia (PCEA) following hip replacement: Ropivacaine versus bupivacaine. Acta Anaesthesiol Scand. 2001;45:782-5.

[7] Kanai A, Kinoshita S, Suzuki A, Okamoto H, Hoka S. Advantage of ropivacaine for postoperative epidural analgesia following leg orthopedic surgery. Masui. 2005;54:8-13

[8] Sawhney KY, Kundra S, Grewal A, Katyal S, Singh G, Kaur A, et al. A randomized double blinded comparison of epidural infusion of bupivacaine, ropivacaine, bupivacaine-fentanyl, ropivacaine-fentanyl for postoperative pain relief in lower limb surgeries. J Clin Diagn Res. 2015;9:UC19-23.

[9] Jagtap S, Chhabra A, Dawoodi S, Jain A. Comparison of intrathecal ropivacaine-fentanyl and bupivacainefentanyl for major lower limb orthopaedic surgery: A randomised double-blind study. Indian J Anaesth. 2014;58:442-6

[10] Khanna A, Saxena R, Dutta A, Ganguly N, Sood J. Comparison of ropivacaine with and without fentanyl vs. bupivacaine with fentanyl for postoperative epidural analgesia in bilateral total knee replacement surgery. J Clin Anesth. 2017;37:7-13. 